\title{
Lightbot Logicamente: um game lúdico amparado pelo Pensamento Computacional e a Matemática
}

\author{
Daniella Santaguida Magalhães de Souza ${ }^{3}$, Maria Luiza Ferrarini Goulart ${ }^{3}$, \\ Graziela Ferreira Guarda ${ }^{1}$, Ione Ferrarini Goulart ${ }^{2}$ \\ ${ }^{1}$ Departamento de Computação - Universidade Católica de Brasília (UCB) \\ Campus I - QS 07 - Lote 01 - EPCT - Águas Claras - Brasília - DF CEP: 71966-700. \\ ${ }^{2}$ Área de Informação e Comunicação - Instituto Federal de Brasília (IFB) \\ Campus Brasília - SGAN 610 Módulo D, E, F e G - CEP: 70830-450. \\ ${ }^{3}$ Departamento de Matemática - Universidade de Brasília (UnB) \\ Campus Universitário Darcy Ribeiro - Brasília - DF CEP: 70910-900. \\ dani.smsehotmail.com, marialuizafgegmail.com, \\ grazielafguarda@gmail.com, ionefg@gmail.com
}

\begin{abstract}
The present study presents a case studies about a playful game based on the game virtual Lightbot. The experience was the result of the activities of a research project called Logicamente, that aims to use tools to spread the teaching of programming logic and algorithms with support of mental tools of Computational Thinking. In this sense, the game course, Lightbot exploring playful manner and with broader complexity, the use of logical sequences to meet a specific set of instructions. The game was still reinforced by elements of mathematics, considered a differential implementation proposal.
\end{abstract}

Resumo. O presente estudo apresenta um relato de experiência acerca de um jogo lúdico baseado no jogo virtual Lightbot. A experiência foi fruto do conjunto de atividades de um projeto de pesquisa chamado Logicamente, que tem como finalidade utilizar ferramentas para propagar o ensino de lógica de programação e algoritmos com apoio das ferramentas mentais do Pensamento Computacional. Neste sentido, surgiu o jogo Lightbot Logicamente, que explora de maneira lúdica e com grau de complexidade mais amplo, o uso de sequências lógicas para atender um determinado conjunto de instruções. $O$ jogo foi reforçado ainda por elementos da matemática, considerado um diferencial da implementação proposta.

\section{Introdução}

No Brasil, diferentes instrumentos de avaliação como: o Sistema de Avaliação da Educação Básica (SAEB), o Índice de Desenvolvimento da Educação Básica (IDEB), o Exame Nacional do Ensino Médio (ENEM), o Exame Nacional para Certificação de Competências de Jovens e Adultos (ENCEJA) [INEP 2018] mapeam, em uma parte significativa dos estudantes dos ensinos fundamental e médio, o baixo nível de proficiência na disciplina de matemática.

Este baixo nível de proficiência se reflete nas diferentes dificuldades enfrentadas pelos estudantes no processo de ensino-aprendizagem de matemática, e que são objetos de pesquisas e temas recorrentes de eventos acadêmicos cujo objetivo é tentar identificar as origens destes problemas. Neste sentido, segundo [Smith 2001], as causas 
VII Congresso Brasileiro de Informática na Educação (CBIE 2018)

Anais do XXIV Workshop de Informática na Escola (WIE 2018)

das dificuldades podem estar tanto no estudante quanto nos fatores externos. Em relação aos aspectos referentes aos estudantes, é importante considerar e observar problemas de memorização, atenção, atividade perceptivo-motora, organização espacial, habilidades verbais e/ou falhas estratégicas como possíveis fatores responsáveis pelos déficits de aprendizagem.

Do mesmo modo, [Sanchez 2004] também destaca que as dificuldades de aprendizagem em matemática podem se manifestar de diferentes formas, na qual se destacam as dificuldades inerentes à própria complexidade da matemática - como seu alto nível de abstração e generalização, a complexidade dos conceitos, algoritmos e a natureza lógica e exata de seus processos.

Em paralelo, é notória a inclusão e influência das Tecnologias da Informação e Comunicação (TICs) nos processos educacionais [UNESCO 2015]. O uso das TICs com o público-alvo infanto-juvenil é algo instigante cujas perspectivas são motivadoras, pois este é um público bastante habituado ao uso desses recursos, de modo que se torna interessante buscar maneiras de se contribuir com a aprendizagem de uma maneira divertida e agradável com objetivo de aperfeiçoar a capacidade lógica desses estudantes, e também, fazer um refinamento das competências relacionadas à concentração, à colaboração e à análise.

Neste sentido, surge o conceito do Pensamento Computacional (PC) como instrumento interventor que auxilia na resolução de problemas, projeção de sistemas, e compreensão do comportamento humano, baseado nos conceitos fundamentais da ciência da computação. O PC dispõe de uma série de ferramentas mentais que refletem a amplitude do campo das ciências exatas [Wing 2006].

O presente relato visa contribuir para a construção de um processo de ensinoaprendizagem gamificado, no qual o desenvolvimento do raciocínio lógico, matemático e computacional é estimulado através de práticas que abordam a montagem de sequências lógicas de forma estruturada em um ambiente de computação desplugada.

Este artigo está dividido da seguinte maneira: a seguir, na Seção 2, é apresentada uma explicação sobre o jogo e a metodologia utilizada, bem como, sua organização estrutural. Os resultados parciais são descritos na Seção 3. Por fim, os objetivos e metas desta experiência serão destacados na Seção 4, de forma a concluir o propósito do jogo diante dos resultados já obtidos, bem como, relatar a perspectiva de resultados futuros e melhorias que poderão ser integradas posteriormente.

\section{Proposta e Metodologia}

O conceito do jogo surgiu proveniente da necessidade de dar prosseguimento, de maneira prática, a conteúdos teóricos que foram abordados pelo projeto de pesquisa Logicamente, cujo enfoque é trabalhar as diretrizes do PC nos níveis fundamental e médio da Educação Básica.

Dentre os assuntos trabalhados e objetos de aprendizagem utilizados pelo projeto se destacou o jogo digital educativo Lightbot que serviu de inspiração para a criação do lúdico em questão. O público-alvo foram os estudantes do ensino médio de uma escola particular do Distrito Federal (DF).

O Lightbot se trata de jogo educacional que proporciona uma experiência divertida induzindo o raciocínio lógico ensinando aos jogadores os comandos básicos de 
VII Congresso Brasileiro de Informática na Educação (CBIE 2018)

Anais do XXIV Workshop de Informática na Escola (WIE 2018)

programação. A plataforma utiliza comandos que fazem referência direta aos algoritmos computacionais explorando as estruturas sequenciais, de seleção, de repetição e de funções/procedimentos sem a necessidade de compreensão de escrita de pseudocódigos.

O jogo conta com um robô cuja função é realizar um percurso dentro de um labirinto ( $\mathrm{N}^{\circ} 4$ - Figura 1) com determinado número de jogadas. O jogador visualiza um bloco de ações principal MAIN ( $\mathrm{N}^{\circ} 1$ - Figura 1) e outros dois de ações secundárias PROC1 e PROC2 ( ${ }^{\text {os }} 2$ e 3 - Figura 1). O robô pode executar comandos como: andar para frente, virar à direita, virar à esquerda, pular, acender a luz e acionar procedimentos repetitivos, e essas orientações ou conjunto de ações que podem ser executadas pelo robô, devem ser informados no bloco principal utilizando os comandos $\left(\mathrm{N}^{\circ} 5\right.$ - Figura 1) para montar a sequência lógica a ser executada.

Há também a opção do uso de estruturas de repetição, que se configuram em um conjunto de ações que podem acontecer mais de uma vez dentro de uma mesma rodada. Esse conjunto de ações fica pré-definido e só há a necessidade de escrevê-lo uma única vez para, sempre que necessário, reutilizá-lo. No caso do Lightbot, o jogo só permite a criação de dois procedimentos que se refere aos comandos P1 e P2 ( $\mathrm{N}^{\circ} 5$ - Figura 1).

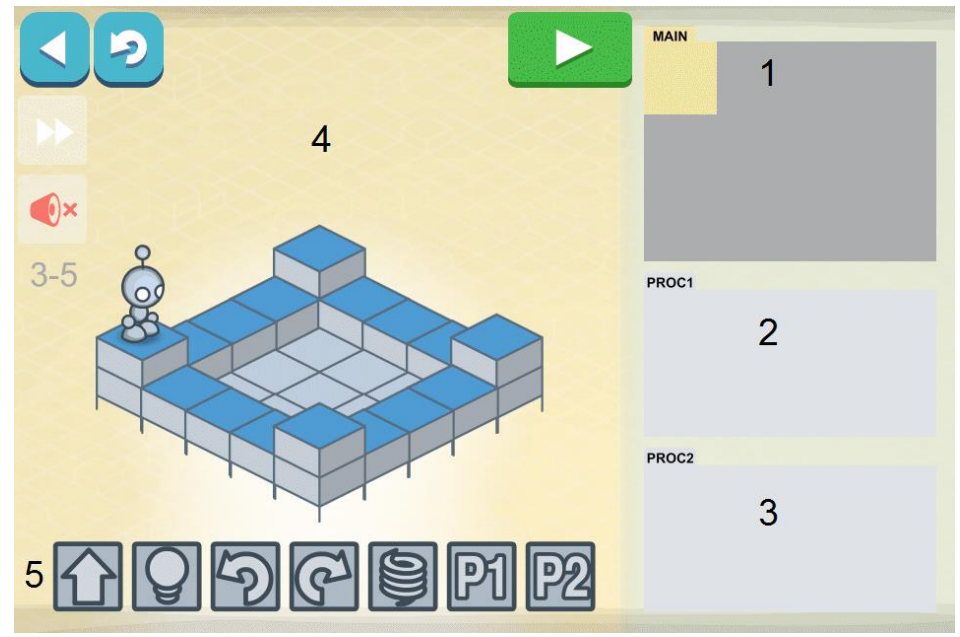

Figura 1. Cenário do Lightbot

Tabela 1. Descrição do Cenário Lightbot

\begin{tabular}{|c|c|c|}
\hline $\mathbf{N}^{\mathbf{o}}$ & Nome & Descrição \\
\hline 1 & MAIN & $\begin{array}{l}\text { Bloco de ação onde os comandos são colocados. É o bloco } \\
\text { principal, onde rodam as primeiras ações do robô. }\end{array}$ \\
\hline 2 & PROC1 & $\begin{array}{l}\text { Caso seja utilizado, é um bloco de ações extras, que pode } \\
\text { servir para estruturas de repetição - loops. }\end{array}$ \\
\hline 3 & PROC2 & Idem PROC1. \\
\hline 4 & Área principal & $\begin{array}{l}\text { Labirinto onde o robô realizará as ações do MAIN } \\
\text { ("tabuleiro"). }\end{array}$ \\
\hline 5 & Comandos & $\begin{array}{l}\text { Seta para cima: o robô anda uma casa para frente. } \\
\text { Lâmpada: o robô acende a luz da casa em que se encontra. } \\
\text { Seta no sentido anti-horário: o robô vira para sua esquerda. } \\
\text { Seta no sentido horário: o robô vira para sua direita. } \\
\text { Mola: o robô pula para a casa a sua frente. } \\
\text { P1: executa o bloco de ações que estão no PROC1. } \\
\underline{\text { P2: executa o bloco de ações que estão no PROC2. }}\end{array}$ \\
\hline
\end{tabular}


VII Congresso Brasileiro de Informática na Educação (CBIE 2018)

Anais do XXIV Workshop de Informática na Escola (WIE 2018)

Após os estudantes do ensino médio terem conhecido e experimentado o jogo Lightbot na versão online original, foi identificado que a quantidade de fases e complexidades das mesmas foram consideradas insatisfatórias por parte do públicoalvo, no entanto, a concepção e a estrutura do jogo foi considerada muito interessante por todos, ou seja, os estudantes se mostraram muito interessados no jogo e queriam a oportunidade de jogar mais.

Neste contexto, idealizou-se a construção de um lúdico desplugado, afinal atividades desplugadas facilitam a compreensão de assuntos básicos, possibilitando também a conexão a outros assuntos mais complexos [Ferreira et al 2015]. Este lúdico foi inspirado no tabuleiro do Ligthbot com regras diferenciadas contendo um adicional de jogadas com grau de complexidade bem mais amplo para atender as expectativas dos estudantes.

Para os estudantes se familiarizarem com o jogo proposto, intitulado como Lightbot Logicamente, e podermos explorar mais as possibilidades de ensinoaprendizagem, foi realizado num primeiro momento de modo online e depois de maneira desplugada [Cândido et al 2017], ou seja, sem o uso de programas específicos; como podemos observar na Figura 2, que mostra o tabuleiro do jogo.

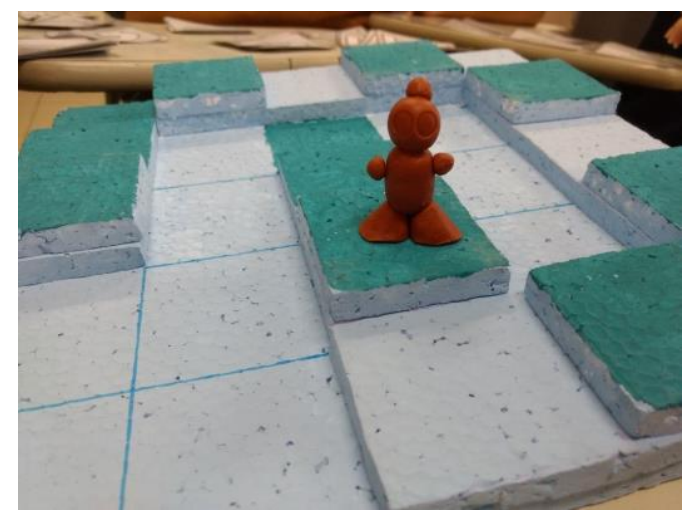

Figura 2. Tabuleiro do Lightbot Logicamente

Na Figura 3, observa-se dois quadros representando o MAIN, o P1 e o P2 respectivamente os números 1, 2 e 3 da Figura 1. Foi também colocada a regra que os estudantes só poderiam utilizar doze comandos no bloco Principal (MAIN), oito no bloco P1 e mais oito no bloco P2, a fim de limitar o número de ações e colocar um grau de dificuldade maior no jogo desplugado.

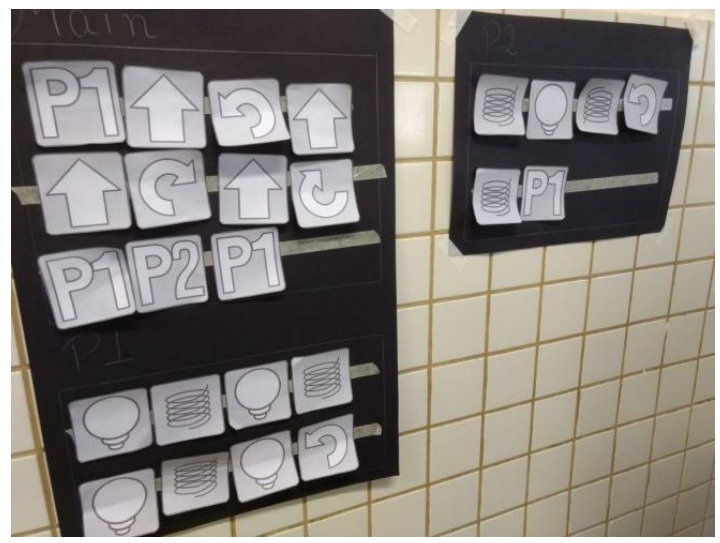

Figura 3. Comandos do Lightbot Logicamente 
VII Congresso Brasileiro de Informática na Educação (CBIE 2018)

Anais do XXIV Workshop de Informática na Escola (WIE 2018)

A Figura 4 demonstra o jogo sendo executado por um dos grupos de estudantes. Observa-se que os pontos do tabuleiro pintado de verde escuro (partes mais escuras) são os pontos do circuito onde o robô precisa chegar para que a pergunta seja feita e se respondida corretamente, o grupo pode dar continuidade ao circuito.

O jogo contou com a divisão da turma em grupos de quatro integrantes e todos tiveram 40 minutos para realização da tarefa, de modo que neste tempo, deveriam achar uma solução para o tabuleiro, e em seguida, responder às questões. O primeiro grupo que terminasse $\mathrm{o}$ tabuleiro $\mathrm{e}$ respondesse às questões (sem verificação do gabarito/correção) no menor tempo ganharia o jogo. Eles não poderiam contar com ajuda de algum monitor ou professor, nem de celulares ou materiais de consulta; e para fins de critério de desempate, venceria o grupo que respondesse o maior número de questões corretamente.

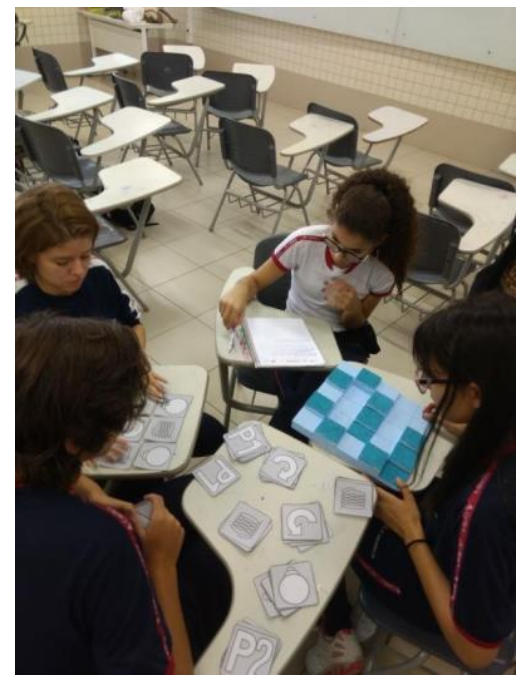

Figura 4. Execução do Lightbot Logicamente

Além disso, para o jogo ficar mais interessante e fortalecer os conteúdos da área da matemática, já que um requisito fundamental para a aprendizagem de matemática é que o ensino por meios de algoritmos e lógica de programação deve atuar como uma ferramenta motivacional e facilitadora [Lopes et al 2016], ao invés dos estudantes fazerem o robô acender a luz (como no jogo online, e que seria um item difícil na versão lúdica), eles deveriam responder a uma pergunta, que podiam ser baseadas na Olimpíada Brasileira de Matemática (OBM) referente ao Ensino Fundamental ou uma outras criadas para o Lightbot Logicamente.

A Tabela 2 mostra algumas das questões utilizadas no lúdico - as questões da OBM sofreram ajustes e adaptações no texto.

Tabela 2. Questões respondidas do Lightbot Logicamente

\begin{tabular}{|c|l|c|c|}
\hline $\mathbf{N}^{\mathbf{0}}$ & \multicolumn{1}{|c|}{ Questões } & Alternativas & Gabarito \\
\hline 1 & $\begin{array}{l}\text { Um copo de base quadrada, com lado } 4 \mathrm{~cm} \text { e altura de } \\
7 \mathrm{~cm} \text {, foi preenchido com líquido até sua borda. }\end{array}$ & - & $\begin{array}{l}\text { Não } \\
\text { transborda }\end{array}$ \\
$\begin{array}{l}\text { Queremos passar o líquido para outro copo de base } \\
\text { circular, de raio 3 cm e de altura } 10 \mathrm{~cm} \text {. O líquido irá } \\
\text { ou não transbordar? }\end{array}$ & $\begin{array}{l}\text { Qual o valor da expressão: }\left(2016^{2}-1\right) / 2015[\mathrm{OBM} \\
\text { 2016] }\end{array}$ & - & 2017 \\
\hline
\end{tabular}


VII Congresso Brasileiro de Informática na Educação (CBIE 2018)

Anais do XXIV Workshop de Informática na Escola (WIE 2018)

\begin{tabular}{|l|l|l|l|}
\hline 3 & Dona Maria fez uma grande pizza para seus filhos no & a) 12 & d \\
& Dia das Mães, mas não tinha certeza se viriam visitá-la & b) 18 & \\
dois, três ou cinco filhos. Ela quer deixar a pizza & c) 24 & d) 30 \\
dividida em pedaços iguais antes da chegada dos fillhos & e) 60 & \\
e faz questão de que aqueles que vierem comam a & & \\
mesma quantidade de pizza. Qual é o menor número de & pedaços em que ela deve dividir a pizza? [OBM 2016] & & \\
\hline
\end{tabular}

\section{Resultados e Discussões}

A experiência do Lightbot Logicamente foi realizada em novembro de 2017, com oito dos treze estudantes de $1^{\circ}$ e $2^{\circ}$ ano do ensino médio que participaram do projeto, desta forma, foi possível a criação de dois grupos com quatro integrantes cada.

O tempo de duração da atividade foi pensado de acordo com o tempo da aula do projeto, ou seja, $1 \mathrm{~h} 40 \mathrm{~m}$, distribuídos da seguinte forma: 20 minutos para a organização e orientações; 65 minutos de prova e 15 minutos para premiação e entrevista. Porém, como houve um imprevisto com a reserva da sala de aula que ocorreria a atividade lúdica, tivemos um atraso de aproximadamente 30 minutos, fazendo que fosse preciso rever e reestruturar o tempo destinado à atividade; ficando da seguinte maneira: 10 minutos para a organização e orientações; 45 minutos de prova e 15 minutos para a premiação e entrevista.

Vencida a barreira da reserva da sala e da redistribuição do tempo, a atividade foi iniciada. Os estudantes iam testando as várias possibilidades para a resolução do tabuleiro e alguns chegaram bem perto da solução, mas acabavam voltando ao início, e isso fez com que o tempo da prova se tornasse insuficiente, e se não fosse aumentado, corríamos o risco de não conseguir finalizar a atividade. Ao nos depararmos com mais esta barreira, foi preciso reajustar o tempo de prova, sendo acrescidos 5 minutos e depois mais 10 minutos, totalizando um acréscimo de 15 minutos ao tempo de 45 minutos de prova, ou seja, a prova acabou ficando com duração de 60 minutos. Desta forma, os grupos puderam concluir a solução do tabuleiro e montá-la nos respectivos quadros (Figura 3).

Percebeu-se ainda outros dois pontos que ocasionaram a necessidade de prorrogação do tempo de prova, que foram: a dificuldade que os estudantes encontraram com as operações aritméticas e uma das regras do jogo. A regra era que se o grupo errasse alguma questão, perderiam todos os pontos obtidos pelas perguntas corretas respondidas anteriormente e deveriam voltar ao ponto inicial do tabuleiro e não de onde pararam na última resposta correta. Vale ainda aqui ressaltar, que quando eles precisavam voltar no tabuleiro, eram selecionadas novas perguntas, ou seja, as perguntas não se repetiam. Desta forma, o grupo 1 tornou-se vencedor do Lightbot Logicamente conseguindo resolver três questões corretamente, enquanto o grupo 2 resolveu apenas uma.

Sendo assim, logo após a premiação ser feita ao grupo 1, foi realizada uma entrevista com todos os estudantes que participaram do Lightbot Logicamente. Estas entrevistas foram gravadas com a ajuda de um aparelho celular e depois transcritas, a título de registro e também documentação para uso conforme conveniência do projeto de pesquisa Logicamente.

A Tabela 3, abaixo, apresenta as perguntas feitas nas entrevistas com os grupos 
VII Congresso Brasileiro de Informática na Educação (CBIE 2018)

Anais do XXIV Workshop de Informática na Escola (WIE 2018)

após o término do jogo, e logo abaixo da tabela, discorremos sobre algumas percepções sobre as respostas.

Tabela 3. Entrevista

\begin{tabular}{|c|c|}
\hline Perguntas & Respostas \\
\hline $\begin{array}{l}\text { Qual foi o nível de dificuldade do desafio? } \\
\text { Defina uma nota entre } 0 \text { e } 10 \text {, sendo zero a } \\
\text { nota mínima e dez a nota máxima. }\end{array}$ & $\begin{array}{l}\text { Grupo 1: os estudantes responderam } 3,5,7,8 \text {, } \\
\text { respectivamente. } \\
\text { Grupo 2: todos os quatro responderam } 7 .\end{array}$ \\
\hline $\begin{array}{l}\text { Como foi a experiência do trabalho em } \\
\text { equipe e divisão das tarefas? }\end{array}$ & $\begin{array}{l}\text { Grupo 1: Todos consideraram uma experiência } \\
\text { positiva. Um deles disse que tem déficit de } \\
\text { atenção, por isso achou que teve dificuldade de } \\
\text { adaptação. } \\
\text { Grupo 2: Todos consideraram uma experiência } \\
\text { positiva, pois assim visualizaram mais opções } \\
\text { para construção da sequência lógica. }\end{array}$ \\
\hline $\begin{array}{l}\text { Qual foi a maior dificuldade encontrada: } \\
\text { montar a sequência lógica ou responder às } \\
\text { perguntas? }\end{array}$ & $\begin{array}{l}\text { Ambas as equipes acharam que montar a sequência } \\
\text { lógica foi mais complexo do que as perguntas. }\end{array}$ \\
\hline $\begin{array}{l}\text { O tempo determinado para realização da } \\
\text { experiência foi suficiente? }\end{array}$ & $\begin{array}{l}\text { Grupo 1: Foi relatado que a delimitação do tempo } \\
\text { os fez se organizarem melhor e consequentemente } \\
\text { pensar mais rápido, embora tenham se sentido } \\
\text { prejudicados, ao final, para responder as questões. } \\
\text { Grupo 2: Foi relatado que a delimitação do tempo } \\
\text { foi prejudicial para o andamento da atividade, o } \\
\text { grupo considerou que sem essa regra, } \\
\text { provavelmente, teriam mais facilidade para } \\
\text { montar a sequência lógica e conseguiriam } \\
\text { responder todas as questões. }\end{array}$ \\
\hline $\begin{array}{l}\text { Em relação a sua participação, sua } \\
\text { contribuição especificamente foi relevante } \\
\text { e aproveitada? }\end{array}$ & $\begin{array}{l}\text { Ambos os grupos relataram que a sinergia foi boa } \\
\text { e que todas as contribuições foram registradas e } \\
\text { aproveitadas. }\end{array}$ \\
\hline No geral, o que você achou do desafio? & $\begin{array}{l}\text { Ambos os grupos relataram que a experiência foi } \\
\text { rica, que gostaram bastante do desafio e } \\
\text { recomendariam para amigos. }\end{array}$ \\
\hline
\end{tabular}

Considerando os dados da Tabela 2, cujo objetivo foi validar as impressões obtidas da experiência do jogo lúdico, se destacaram como aspectos positivos o trabalho em equipe e a divisão das tarefas, que nas opiniões individuais - para a montagem das sequências lógicas - foram respeitadas e levadas em consideração nas tomadas de decisão e por fim, que foi o jogo foi bem elaborado, divertido, instigante e que seria recomendado para outras pessoas como instrumento pedagógico.

Em relação ao nível de dificuldade, as opiniões foram divididas, mas no geral, a média das notas dadas foi 6,375 o que representa uma nota média, que precisa ser melhorada e nos servirá como reflexão para aprimoramento do objeto de aprendizagem. Apesar da resposta dos estudantes quanto à dificuldade, observamos que na prática, muitos tiveram grandes obstáculos para a resolução do tabuleiro e não souberam dividir o tempo para as perguntas, que são em maioria de nível fundamental. Quanto ao tempo, as opiniões também foram divididas, um grupo compreendeu a delimitação do tempo como um desafio positivo e outro como "pressão" que acarretou em um desempenho inferior por parte dos integrantes do grupo. 
Um ponto importante constatado é que dentre as dificuldades relatadas, a montagem da sequência lógica se sobrepôs aos desafios matemáticos e esse é justamente o foco do projeto de pesquisa, disseminar conhecimentos acerca de raciocínio lógico, matemático e lógica de programação com apoio das ferramentas mentais do pensamento computacional. Esses desafios nos levam a reflexão sobre as transformações digitais na qual estamos inseridos e que algo dessa natureza exige da humanidade novas habilidades cognitivas e novas competências, que é algo que o projeto vem buscando fortemente.

\section{Considerações Finais}

O presente trabalho teve como tema central a utilização das diretrizes do PC como instrumento de apoio e resolução de problemas destacando os assuntos referentes à lógica matemática. $\mathrm{O}$ intuito foi mostrar que essas diretrizes estão em todas as ações cotidianas e retratar a importância de sabermos utilizar o PC para superar obstáculos e dificuldades, em especial os da área da matemática.

Através do desafio proposto, os estudantes utilizaram os comandos - sequências lógicas - para atravessar um tabuleiro, em modelo real, respondendo a perguntas matemáticas, para associar as habilidades de cooperação, de competição, de raciocínio lógico e de agilidade. O lúdico abordou, ainda, a importância do ensino de programação e reforçou os conteúdos estudados nas atividades realizadas pelo projeto durante seu ano de execução.

Com o aprendizado de programação, os jovens conseguem aprimorar suas competências e habilidades, por isso, o projeto Logicamente tem como meta trabalhar com jogos relacionados às competências do PC para aprimorar todas as áreas de conhecimento, não apenas a Matemática.

$\mathrm{O}$ uso de um jogo lúdico foi uma maneira interessante para trabalhar as temáticas com o público-alvo. Neste sentido, o objetivo foi alcançado, pois foi possível constatar que os estudantes trabalharam sua concentração, sua colaboração no trabalho em equipe e aprimoraram seus conhecimentos na área de programação e algoritmos, assim como, na área de lógica e resolução de problemas, fazendo uso do PC para a solução do desafio proposto, não podendo deixar de ressaltar que o jogo foi recebido com entusiasmo por parte dos estudantes, que ficaram empolgados e motivados com o conteúdo e metodologia aplicada.

Por fim, como trabalhos futuros, se pretende implantar as melhorias advindas dos aspectos negativos detectados da experiência e pensar na criação de novos objetos de aprendizagem que explorem os conteúdos abordados como reforço escolar, almejando o aumento da proficiência nas disciplinas das ciências exatas nos ensinos médio e fundamental e também as habilidades de computação tão necessárias atualmente.

\section{Referências Bibliográficas}

CÂNDIDO, Daniel et al. Estudo Comparativo de Abordagens Referentes ao Desenvolvimento do Pensamento Computacional. In: WORKSHOP DE INFORMÁTICA NA ESCOLA, 23, 2017, Recife. Anais. Recife: Sociedade Brasileira de Computação - SBC, 2017. p. 382 - 391. 
VII Congresso Brasileiro de Informática na Educação (CBIE 2018)

Anais do XXIV Workshop de Informática na Escola (WIE 2018)

FERREIRA, Ana Carolina C. et al. Experiência Prática Interdisciplinar do Raciocínio Computacional em Atividades de Computação Desplugada na Educação Básica. In: WORKSHOP DE INFORMÁTICA NA ESCOLA, 21, 2015, Maceió. Anais. Maceió: Sociedade Brasileira de Computação - SBC, 2015. p. 256 - 265.

INSTITUTO NACIONAL DE ESTUDOS E PESQUISAS EDUCACIONAIS ANÍSIO TEIXEIRA INEP. Educação Básica. Disponível em: <http://portal.inep.gov.br/web/guest/educacao-basica>. Acesso em: 07 jun. 2018.

LOPES, Claudivan Cruz et al. O Ensino de Algoritmos e Lógica de Programação como uma Ferramenta Pedagógica para Auxiliar a Aprendizagem de Matemática: Um Relato de Experiência. In: WORKSHOP DE INFORMÁTICA NA ESCOLA, 22, 2016, Uberlândia. Anais. Uberlândia: Sociedade Brasileira de Computação - SBC, 2016. p. 51 - 50.

OLIMPÍADA BRASILEIRA DE MATEMÁTICA (Brasil) (Org.). 38 ${ }^{\mathbf{a}}$ Olimpíada Brasileira de Matemática - Primeira Fase - Nível 1.2016. Disponível em: <https://pt.scribd.com/document/376854694/N1-Fase1>. Acesso em: 08 out. 2017.

SÁNCHEZ, Jesús-nicasio García. Dificuldades de Aprendizagem e Intervenção Psicopedagógica. Porto Alegre: Penso, 2004. 296 p.

SMITH, Corinne; STRICK, Lisa. Dificuldades de aprendizagem de A a Z: guia completo para educadores e pais. Porto Alegre: Penso, 2012. 398 p.

UNESCO. TIC na educação do Brasil. Disponível em: $<$ http://www.unesco.org/new/pt/brasilia/communication-and-information/access-toknowledge/ict-in-education/>. Acesso em: 07 jun. 2018.

WING, Jeannette M.. Computational thinking. Communications Of The Acm, [s.1.], v. 49, n. 3, p.33-35, 1 mar. 2006. Association for Computing Machinery (ACM). http://dx.doi.org/10.1145/1118178.1118215. 